\title{
2
}

\section{The Internet Journey for Kenya: The Interplay of Disruptive Innovation and Entrepreneurship in Fueling Rapid Growth}

\section{Muriuki Mureithi}

\section{Introduction}

Kenya's information and communication technology (ICT) sector has witnessed a dramatic turnaround. Barely 20 years ago, in the mid-1990s, the sector was an irritant to the political system and was best discussed by geeks in hushed tones. The political system saw emerging ICTs as an affront to challenge its leaders' power and control over information flow. Such was the environment that the first efforts to introduce the Internet in Kenya, in 1995, were met with an official rebuff through a fullpage advertisement by the then Kenya Posts and Telecommunications Corporation (KP\&TC), a monopoly state enterprise, declaring that Internet services amounted to resale, and were therefore illegal. It was in this harsh environment that the Internet was born in Kenya. In short order, it was banned entirely in the government civil service until 1999.

In such an environment, the Internet was only for brave nongovernment organizations (NGOs), geeks, and small companies with

M. Mureithi $(\bowtie)$

Summit Strategies Ltd, Nairobi, Kenya

(C) The Author(s) 2017

B. Ndemo, T. Weiss (eds.), Digital Kenya,

DOI 10.1057/978-1-137-57878-5_2 
international business interests. Indeed, none of the universities had Internet connections. Concerted advocacy changed the tide, and by 1997 , the government promulgated the Telecommunication and Postal Sector Policy recognizing ICT's contributions to development, and by 1999 , passed the Kenya Information and Communication Act, a new telecom law establishing a multi-operator environment-followed shortly thereafter by official recognition of the Internet. However, the market still had to endure a monopoly international gateway through the state-owned incumbent operator for another seven years, till 2007.

The Telecommunication and Postal Sector Policy had envisaged a national teledensity (i.e., telephone lines per 100 people) of $5 \%$ by 2015. But in fact, rapid growth realized a teledensity of fully $88 \%$ by September 2015 (Communications Authority of Kenya 2015).

In the two decades before 2015, the sector came of age, and so did the institutions driving the Internet. Today, the Government of Kenya has now fully embraced the Internet and ICTs as drivers of socioeconomic growth and, in a very bold move, established a high-level agency to mainstream e-government as a tool for governance and for reaching out and interacting with the nation's citizens. Working with various stakeholders, the government has even promulgated a national ICT policy that actively envisages national growth driven by ICTs.

Slowly but surely, new and revolutionary technologies and business processes have come into the market, disrupting older technologies and business processes. The policy and regulatory framework has had to give way to respond to the new environment, and finally, the early actors have had to give way to new actors. Indeed, none of the key actors from 20 years ago exist in 2015. KP\&TC, for example, has given way to Telkom Kenya, which is quite different from the old monopoly, KP\&TC.

The evolution is profound. At the technology level, Kenya has moved from offline store-and-forward (FidoNet) technologies and reliance on copper for connectivity to cellular, and now, to fiber optics. Similarly, the bandwidths of 2015 would have been inconceivable two decades ago. In September 1995, Kenyan Internet users shared 32 Kbps to serve the entire country - a far cry from the 1.7 Gbps available 20 years later. From the international NGOs who introduced email, Internet service is for the masses today and is used by many in daily activities. The Kenyan government, which through KP\&TC was dead set against email and 
Internet and banned it in government services, is now a key promoter of a digital future for Kenya.

The net effect is that the Internet is widely available and much cheaper, with applications for numerous aspects of daily life. Still, $26 \%$ of Kenyans are not using the Internet for various reasons, including gender disparities in access and use, affordability, content relevance, and basic access. This chapter attempts to document the disruptions that have brought Kenya this far over the past 20 years and to explore lessons that can help guide the nation over the coming 20 years - while addressing new frontiers that have not so far benefited from the rise of the Internet.

\section{Evolution of ICTs}

The evolution of ICTs has been very fast and has affected all stakeholders - users, operators, and the government. The following phases can be discerned in the evolution of ICTs in Kenya and the role of civil society organizations (CSOs):

- Phase 1 Before 1994, electronic communications other than email were hardly known. Users were largely international NGOs for international communications. Email service providers relied on upstream Internet service providers (ISPs) based abroad to poll its servers once or twice a day to collect and deposit mail. The upstream ISPs distributed the mail globally. Because of the high cost of leased lines, calls were reversed, that is, instead of Kenyan operators initiating calls, the calls would be initiated from abroad. The Association of Progressive Communications (APC) network of organizations was one of the principal upstream distribution supports for local email service providers.

- Phase 2 In this phase, awareness of the Internet increased and email was launched. A milestone workshop organized by the Telecommunications Foundation of Africa in July 1995 attracted ten email service providers - a relatively high attendance, reflecting a growing interest in understanding the new technology. Immediately after the workshop, KP\&TC made its declaration that Internet services were an illegal use of leased lines. 
- Phase 3 In 1994 and 1995, the African Regional Centre for Computing launched a full Internet system with financial support from the British Government's Overseas Development Agency to pay for an international leased line. With increased awareness, clear business opportunities were emerging and attracting private-sector businesses that wished to launch commercial Internet services. Regulatory and operational bottlenecks affected access to bandwidth, however, leading to very high costs of access for consumers. The role of the CSOs as suppliers of Internet services declined dramatically because of competition from commercial operators. Funding of Internet development also evolved, from donor funding to commercial funding by entrepreneurs.

- Phase 4 Since 2000, with the entry of the Communications Commission of Kenya (CCK) as the nation's telecommunications regulator, the government has legally recognized the Internet and established a proactive relationship with $\mathrm{CCK}$ as a development partner. Entry barriers in licensing and fees came down. The government also accepted the Internet as an integral tool for development. Challenges, however, have remained-emerging monopolies, access to rural areas, affordability, the high cost of equipment, and the lack of content.

It is clear that the evolution of the Internet in Kenya has been rapid, with fundamental changes affecting every stakeholder:

- At the institutional level, this evolution has seen a decline in the influence of the East African Internet Association (EAIA), a nonprofit organization founded in 1995, that advocated and catalyzed the growth of the Internet to Telecommunications Service Providers of Kenya, a nonprofit organization representing technology service providers, in order to address the Internet's then-current operational problems.

- The evolution has seen the role of CSOs move from the supply side of services in 1992-1995 to the demand side. Today, the CSOs' concern is to reach higher levels of equity of access in terms of affordability for rural areas and the poor and of application in governance. The private sector drives the supply side on a commercial basis.

- At the operational level, the dominance of the CSOs in driving the growth of the Internet before 1994 has given way to the private sector, and the efficiency of distribution of local mail has been addressed with 
the launch of the Kenya Internet Exchange (an Internet exchange point launched by Kenyan ISPs in 2000 to cut costs by avoiding the use of expensive international links [mostly satellite at the time]).

- At the technology level, FidoNet technology dominated in 1994. Because of the high cost of international calls, operators reversed traffic to upstream ISPs on a periodic basis. Transmission was through KP\&TC, low earth orbiting satellites, and high-frequency radio to rural areas. The technology has since changed to make use of online connectivity after the introduction of the Internet in 1995.

\section{Internet Diffusion and Impacts of Disruptive Innovation}

\section{Network Establishment, from 1990 to 2000}

Technology moved from FidoNet store-and-forward systems being polled by GreenNet in the UK every six hours to a 64-Kbps online link for the country and then to today's high speeds of 1.7 Gbps over the submarine cables in 2015. End users could only reach $14 \mathrm{Kbps}$ to poll into the FidoNet systems, which had a limited number of dial-in lines, all owned by KP\&TC. These have given way progressively from analog first-generation $(1 \mathrm{G})$ systems to today's fourth-generation $(4 \mathrm{G})$ systems as coaxial cables have been superseded by fiber optics.

New technology has also seen disruptions and the consequent demise of planned projects. Regional telecommunications networks, Code Division Multiple Access, trunked radio, and paging networks are some of the planned projects that failed to take off. In addition, innovations have killed legacy technologies and businesses, including postal services, money transfers, and copper-line access.

\section{Offline Technologies}

FidoNet was the technology of choice in the early years, when a customer would have to compose an email message and send it from a computer with a modem to an internet service provider (ISP) server, where it was 
stored. The email would be picked up only after the server had been polled, sometimes up to six hours later, by an upstream ISP (hence the "storeand-forward" terminology). The upstream provider helping most of the NGOs in Africa at the time was GreenNet, established by the Association for Progressive Communications (Levey and Young 2002). The upstream provider would download all email destined for the various Kenya-based NGOs and distribute mail for their international clients. Given the very limited bandwidth, the mail consisted principally of text messages and, rarely, attachments - which had to be encoded by the sender, and then, decoded by the user. It was only after decoding that the user knew if the attachment was, for example, additional text or a spreadsheet.

Email set-up at the customer end was expensive. A customer had to invest in a computer, a modem, and a telephone line. Similarly, the ISPs had to invest in telephone lines ${ }^{1}$ and modems for connectivity to their customers. With a teledensity of less than $1 \%$ nationally, installing the telephone lines was a major barrier-not to mention that the modems had to be of a type approved by KP\&TC (which, incidentally, did not have the skills needed to keep up with approvals for the ever-increasing array of new technologies).

Kenya had deployed mobile cellular in 1992 using Enhanced Total Access Communications System network technology, which-being analog — could not support the Internet.

At USD9 per minute, tariffs for international calls were high-much higher than for a similar call from the UK to Kenya (hence the need to reverse calls so that charges were borne from the UK end).

With all these challenges, the email service was almost entirely for use by international NGOs operating in Kenya (such as the Environment Liaison Centre International [ELCI], African Organisation for Standardisation, and Mission Aviation Fellowship), which provided store-and-forward email services that were largely for communicating with their affiliated organizations - and that were not available to the general public. ELCI was the first to introduce email out of Kenya in 1990 (Levey and Young 2002).

In 1992, electronic mailing was being piloted at the University of Nairobi and the Kenya Medical Research Institute-the earliest local

\footnotetext{
${ }^{1}$ The African Regional Centre for Computing started with two dial-in lines.
} 
encounters with email in Kenya's academic circles (National Research Council 1996).

Outside the major organizations, the African Regional Centre for Computing came on board as a local NGO to offer services to other NGOs and commercial entities. The work of the Centre catapulted Kenya to online connectivity for the first time in October 1995 on a 32-Kbps link to the UK, setting the stage for disruptions that radically changed the communication systems in the country and slowly nibbled away the mighty KP\&TC — whose response was not only to ignore the technology but also to attempt to block it entirely, a decision that has haunted the organization ever since.

\section{Online Internet}

October 1995 was a turning point in Kenya's communications history, when a leased line connection was established, providing Internet for the first time. At $32 \mathrm{Kbps}$, Kenya was at last connected to the Internet, and the dream of information sharing became a reality. The system's bandwidth was low even for those days and not much for information gathering-but now, at least email did not have to wait to be polled up to six hours later.

Shortly thereafter and in quick succession, two ISPs serving the commercial and personal markets-Africa Online (Prodigy USA) and FormNet—started offering service, and for the first time, competition entered the market. By the end of 1995, the two each had a 64-Kbps link and 100 lines to serve their clientele. This opened a floodgate of other operators, and by the end of 1995 , more than 10 were advertising for services, and reported accounts totaled approximately 5000 (Aguyo 1997).

\section{Sector Regulation Defining Connectivity}

Kenya's telecommunications sector was regulated under KP\&TC Act Cap 411, promulgated in 1977. Under this Act, KP\&TC was the exclusive monopoly provider of telecommunications services. It enforced this monopoly with zeal and, when expedient, could spin off services or licences to third parties at its discretion (GOK 1978). 
As an example, KP\&TC sold its paging interest under a five-year exclusive licence to a private company. Other services licensed included providers of customer-premises equipment, telephone bureaus, and Internet services. The discretion afforded to KP\&TC by the Act was used selectively to lock out competitors, and when necessary, to enforce its monopoly powers through the courts. On at least two occasions, entrepreneurs were arraigned in court for operating radio communication services without the approval of KP\&TC.

As a monopoly, KP\&TC controlled all telecommunications services. The emergence of an alternative communications system (albeit one using the same infrastructure) was threatening KP\&TC's stranglehold on the sector, which is why KP\&TC could not support the new service and indeed went all out to stop its use in July 1995. Email services nevertheless continued to grow, but KP\&TC's actions created a very hostile environment. This had a negative impact especially on government email use and that of large corporate organizations. Indeed, the government banned the use of email and the Internet in its communications until 1999.

Eventually, however, the winds of change across East Africa seeking to dismantle monopoly telecommunications operators had a significant impact in Kenya. In 1996, the government promulgated its first policy envisaging competition among telecommunications services in a liberalized environment (GOK 1996), and by 1999, parliament had enacted a legal framework that ushered in true competition (GOK 1998). The Internet now became fully recognized as a service for development. The year 1999 was therefore a turning point that unshackled the Internet and set the pace for Kenya's growth in the coming decade.

The continuing challenges, however, were the continued control of international connectivity by Telkom Kenya and the last mile to the customer, which the ISPs had to deal with until 2007.

\section{Connectivity}

In the early days, connectivity to customers and to international bandwidth were controlled as a monopoly by KP\&TC, and with KP\&TC's limited capacity, telephone lines were inadequate. Unfortunately, even 
when they were available, the failure rate was extremely high, and leased lines were very expensive.

Because of the lack of the telecommunications services in rural areas, the only available options for reaching out to NGOs were the use of high-frequency radio and low earth orbiting satellites. HealthNet, for example, used low earth orbiting satellites extensively to reach out to its community-based-organization partners in rural areas (National Research Council 1996).

\section{Agents and Market Responses}

KP\&TC managed the telecommunications system as a monopoly, with a total switching capacity of 380,000 lines and slightly more than 269,000 connected customers as at the end of 1997. International services were satellite-based through Atlantic and Indian Ocean Intelsat satellites and two earth stations in the town of Longonot, Kenya. An additional earth station was built in the town of Kericho, Kenya, to serve Japan and later retooled to provide local satellite services by very-small-aperture terminals (VSATs).

At the end of 1997, Kenya had 77,163 people waiting for telephone services but was only capable of connecting 10,000-13,000 lines per year-implying that it would take more than 7 years to connect all the waiters (International Telecommunication Union 1998). Clearly this was a good time to facilitate the entry of fresh capital into the sector rather than crippling the local entrepreneurs. As of the end of April 1998, the number of waiters had increased to 80,000 , and it was clear that unsatisfied demand existed in cellular, data services, and paging largely because of the monopolistic tariffs.

The network was creaking with age and obsolescence because of limited investment. The main switching exchange systems required urgent attention to replace old exchanges and transmission systems that had outlived their useful life and were therefore prone to failure. Several old exchange systems were upgraded. These strategic communication facilities were running on obsolescent crossbar technology that was difficulty to support because spare parts were difficult to procure. In total, 150,000 telephones, or half of the total telecommunications network, were connected 
to exchanges based on old, obsolescent technology. It was just a matter of time before key parts failed and the system became disabled (Mureithi 1999).

In addition to age, the network suffered from serious congestion because of its lack of expansion of facilities, making it difficult to place calls, particularly in industrial areas. Lines to the customer were of copper wire and prone to damage by water, rodents, and cable theft. As a result, failure rates were high. On average, there were 186 faults for every 100 telephones per year, which compared poorly with a world average of 5 faults for every 100 telephones per year (International Telecommunication Union 1999). To address the high failure rate of the last mile, KP\&TC launched Instafone, a fixed wireless service designed to overcome faulty customer lines.

As in other public telecommunications networks in Africa, the dominant product was voice telephony, followed by data services. These brought in annual revenues of USD307 million in fiscal year 1996-1997, making KP\&TC the fifth largest operator in the Africa in revenue terms (International Telecommunication Union 1998).

\section{Customer-Premises Equipment and Telephone Bureaus}

Customer-premises equipment and telephone bureaus, including private automated branch exchange systems, terminal sets, and faxes, had been liberalized since 1991. Product availability and the easy mode of entry into the market segment had brought more than 245 companies into the customer-premises-equipment market, with tangible benefits for the consumer in terms of lower prices, better-quality products, and more reliable support.

In addition, KP\&TC had also licensed 250 telephone bureaus, with many more operating without licences, particularly in residential areas.

\section{Service Offerings That Supported the Emerging Internet}

Three years after the Internet launch, Kenya was on track to develop services that anchored the emerging Internet ecosystem. With its monopoly, 
KP\&TC continued to play a key role in complementing an emerging private sector.

Some of the key infrastructure provided by KP\&TC included data services and leased lines. KP\&TC had introduced Kenpac X25 (packet switched), available since May 1994, with a capacity of 1200 ports; analog leased circuits; and KenStream (64 Kbps), with a capacity of 2000 ports. By 1998, the analog leased lines in use had increased to 1695, and the digital lines had increased to 196 (64 Kbps). KP\&TC also launched a national Internet backbone known as the East African Internet Exchange, with a capacity of up to 30,000 customers by 1998 intended to ensure that $90 \%$ of the population would be within reach of the Internet at local call rates.

To complement the terrestrial infrastructure, which was severely limited, KP\&TC launched Kensat (offering VSAT) and Safarisat (offering Inmarsat) satellite services.

The private sector exploited the KP\&TC infrastructure by launching a range of ISPs, including the African Regional Centre for Computing, Africa Online, Form-Net, Inter-connect, Swift Global, Net 2000, NairobiNet, and Insight Technologies. This unleashed further competition, which brought down prices, increased the points of presence in all major towns, and generally raised Internet awareness.

The greatest challenge was the low level of locally relevant content on the Internet, and therefore, its utility in daily life. Another challenge was in the area of licensing and pricing of leased lines by KP\&TC. ISPs had to pay an initial five-year operating licence fee of USD8330 and an annual operating fee of USD4200. Kenya restricted the use of satellite technologies (e.g., VSAT) that would otherwise have offered cheaper international connectivity and provided more capacity to ISPs than was available through KP\&TC. The restriction was to safeguard KP\&TC's monopoly on international connectivity.

Interest in the Internet was growing. Kenya had 458 Internet hoststhe highest number in any country in Sub-Saharan Africa (International Telecommunication Union 1998). The number of email accounts was estimated at 20,000 and growing rapidly. The total number of dial-up lines was estimated at 600, and the number of .ke domain names at 292.

Cost was also a major barrier in the early years. The costs for Internet dial-up service included installation at USD20, monthly charges of 
USD72, and an hourly use rate of USD5. Use of Internet bureaus was equally expensive, with a fee of USD0.20 per minute. At the same time, access to computers was very limited, because of costs and numbers. By 1997, the estimated number of computers in the country was 50,000 (Aguyo 1997).

The greatest handicap for the development of Internet services was the regulatory restrictions they faced. Access to customers and international bandwidth had to go through Telkom Kenya. ISPs had very little leeway on quality of service to consumers and on input costs-and hence had limited marketing leverage_-as well as limited means for innovation.

\section{Implications for the Knowledge Industry}

Because of the poor infrastructure, the access to, sharing, and storage of information were all still manual. And even with the arrival of the Internet, access to information was still limited because of the limited capacity of the links - with the result that information access was very expensive. Yet the dream of an information society was alive and growing.

The downloading of large files (around $1 \mathrm{MB}$ in those days), especially presentations with graphics, was a nightmare, often taking hours. Users had to visit ISPs for assistance in downloading such files onto floppy disks, Internet surfing was discouraging because of the limited information on the Net, search engines like AltaVista were problematic, and any useful information had to be downloaded immediately because one could not be sure of getting it again on the Net! (Today's Google had yet to come into the market.)

\section{Internet Evolution from 2000 to 2010}

The decade from 2000 to 2010 unleashed the full capacities of the Internet. By the end of 2000, it was clear that local Internet traffic was increasing rapidly but had to be switched from overseas at great cost. The ISPs therefore made the pioneering decision to build the Kenya Internet Exchange to switch local traffic. Unfortunately, it was shut down by the 
regulators for an entire year on the grounds that the traffic exchanged through it contravened the exclusivity of Telkom Kenya.

Finally, with the entry of second-generation (2G) digital cellular communications, it became feasible to use an alternative for carrying Internet traffic through General Packet Radio Service. In line with the existing market structure, cellular operators could not be licensed as ISPs and therefore had to transit their email traffic through other licensed ISPs.

In 2007, the curtain came down on Telkom Kenyas monopoly on international gateway, which brought down many barriers to the Internet. Evolution was driven through connectivity via submarine fiber optic cables in 2009, liberalized international gateways and last- and first-mile solutions, and finally, the convergence in services.

The government came back into the market with initiatives to intervene in areas the private sector was not addressing, specifically in rural areas and in international connectivity. In this regard, the government invested in international submarine fiber optic cables and national fiber connectivity. In addition, the decade saw activities that helped entrench the Internet. These included infrastructure to develop data centers, efforts in the domain name space, and government intervention on costs to enduser terminals by the elimination of certain taxes. The decade, in short, ushered the Internet onto a high-growth path.

\section{Geographical: Network Coverage}

At the advent of email and the Internet in Kenya, the access to the Internet was restricted to the availability of copper lines. With under 300,000 lines nationally ( $80 \%$ in the urban areas), this access was severely limited. Cellular in the early years since 1992 was analog, and the emergence of the GSM standard in 1995 was exclusively voice. It was only on the introduction of General Packet Radio Service in 2002 that an alternative last mile was finally introduced in the market.

Fast growth in cellular rapidly increased the customer based in 2001, as cellular connections overtook fixed lines. This was a typical market disruption, with cellular becoming the platform for Internet access going forward. The rapid growth of cellular with improved technologies from 
$2 \mathrm{G}$ to $4 \mathrm{G}$ and widespread coverage has continued to enhance the Internet experience. From nine base stations in 1995 covering Nairobi City Centre, coverage today is nationwide, reaching $90 \%$ of the population.

\section{Lessons from the Internet Revolution}

The Internet evolution has presented some key lessons:

\section{Disruption Is the Sweetener That Drives Change}

A dynamic environment that spawned disruption and was not limited to the technologies and processes but also included the actors was a key to change. Internet advocacy has seen a large turnover among CSOs because of disruptive pathways to enabling policies. Government-imposed barriers that spawned innovations included banning the Internet outright, closing the Kenya Internet Exchange, and imposing punitive costs.

Defensiveness was a principal barrier thrown up by the incumbents as they defended their positions - sparking innovation and market disruption. This behavior has been consistent and keeps refreshing the market with new and improved services at lower costs.

\section{Disruptive Innovation Is the Weapon against Big Players}

The Internet introduced by the African Regional Centre for Computing was a game changer, and today, all the organizations that did not change have been killed by it.

\section{Disruption Is a Deadly Game}

Many of those who innovated and disrupted others were to undergo the same trials themselves eventually, and unless they transformed themselves in turn, they fell by the wayside. Today, only Wananchi Online still exists as an entity. 


\section{An Agent Is Critical for the Game Change}

CSOs were the pioneer developers and promoters of email service provision in the mid-1990s. After establishing the business case, the private sector came on board and commercialized the Internet - in the process, pushing out the CSOs from an operational role. The CSOs took on a new role in expanding the service, with particular focus on the demand side, based on their advocacy of empowerment, access rights, and personal development.

\section{The Agent Itself Must Change Tactics}

The role of CSOs has changed radically from that of developer and promoters to that of advocates. The rapid evolution of the technology and business models has spawned the rapid rise and fall of the CSOs. None of the CSOs existing in the early days still exist today, except the Computer Society of Kenya. Typical CSOs are cited in Table 2.1.

Table 2.1 Civil society organizations driving Internet evolution

\begin{tabular}{|c|c|}
\hline $\mathrm{CSO}$ & Mission \\
\hline East African Internet Association & Introduce the Internet in the country \\
\hline Kenya National ICT forum & Contribute to formulation of ICT policy \\
\hline National E-Commerce Task Force & $\begin{array}{l}\text { Lobby the government on the } \\
\text { implementation of e-commerce }\end{array}$ \\
\hline $\begin{array}{l}\text { Telecommunications Dealers } \\
\text { Association of Kenya }\end{array}$ & $\begin{array}{l}\text { Bring down the cost of telecom } \\
\text { accessories }\end{array}$ \\
\hline Kenya Information Society & $\begin{array}{l}\text { Catalyze the growth of an information } \\
\text { society }\end{array}$ \\
\hline Telecommunications User Association & $\begin{array}{l}\text { Lobby for service-level agreements with } \\
\text { providers }\end{array}$ \\
\hline $\begin{array}{l}\text { Information Technology Standards } \\
\text { Association }\end{array}$ & Foster IT standards \\
\hline Computer Society of Kenya & $\begin{array}{l}\text { Make information technology more } \\
\text { accessible }\end{array}$ \\
\hline $\begin{array}{l}\text { Telecommunications Service } \\
\text { Providers of Kenya }\end{array}$ & Liberalize Internet provision \\
\hline Linux Chix & $\begin{array}{l}\text { Promote women in computing and the } \\
\text { use of open source }\end{array}$ \\
\hline
\end{tabular}

${ }^{a}$ Rebranded in November 2015 as the technology service providers of Kenya 
The demise of the various CSOs was caused by their narrow focus in the market, and once their issues were addressed, their reasons for existence ceased.

The Kenyan government has come full circle, from being dead set against the Internet in the mid-1990s to embracing it as a key tool for development, and now, intervening in areas that the private sector is not willing to venture into.

\section{Conclusion}

Twenty years of Internet evolution have propelled Kenyans to the edges of a knowledge society and empowered them in profound ways in how they relate, conduct business, and even structure their society. The turning points in this evolution have always revealed passionate individuals out over the stumbling blocks ahead, whether they were of a regulatory nature or the suffering of their fellow citizens caused by lack of services. This combination has been instrumental in disrupting business processes and technologies that did not address societal needs, thereby releasing the power of innovation. This is the power Kenyans need to harness in order to sustain their momentum and to continue to lead as an innovation hub for Africa.

At the same time, the fast growth has spawned growing disparities in Internet use and benefits to society_-including a gender gap (because more men than women use the Internet), a poverty gap (when cost becomes a barrier to access), and an urban-rural gap (because those in rural areas are worse off). These gaps will continue to be a challenge in the next decade. But to judge from the experiences of the past 20 years, they will provide the fertile ground to inspire innovation and new disruptive business processes that can close the gaps and propel all Kenyans into the knowledge society.

\section{References}

Aguyo, S. (1997). Internet benchmarking in Kenya. In H. R. Mgombelo \& M. C. M. Werner (Eds.), Telecommunication for business in Africa. Amsterdam: IOS Press. 
Christensen, C. M. (2001). Assessing your organization's innovation capabilities. Executive Forum, 81(2), 27-37.

Communications Authority of Kenya. (2015, July-September ). First quarter sector statistics report for the financial year 2015/2016. http://www.ca.go.ke/ images/downloads/STATISTICS/Sector\%20\%20Statistics\%20Report\%20 Q1\%202015-16.pdf. Accessed 25 Feb 2016.

Government of Kenya (GOK) (1978). The Kenya posts and telecommunications corporation act, chapter 411. Nairobi: Government Printer.

Government of Kenya (GOK). (1996). The policy framework paper. Economic Reforms for 1996-1998. https://www.imf.org/external/np/pfp/kenya/kenya. pdf. Accessed 25 Feb 2016.

Government of Kenya (GOK). (1998). Kenya information and communications act 1998. http://www.researchictafrica.net/countries/kenya/The_ Kenya_Communications_Act_1998.pdf. Accessed 25 Feb 2016.

International Telecommunication Union (ITU) (1998). African telecommunications indicators 1998. Geneva: ITU.

International Telecommunication Union (ITU) (1999). Challenges to the Network: Internet for Development, Geneva, ITU

Levey, L. A., \& Young, S. (Eds.) (2002). Rowing upstream: Snapshots of pioneers of the information age in Africa. Johannesburg: Sharp Sharp Media.

Mureithi, M. (1999). Liberalizing telecommunications: Empowering Kenyans in the information age. Nairobi: Institute of Economic Affairs.

National Research Council (1996). Bridge builders: African experiences with information and communications technology. Washington, DC: National Academy Press. 


\section{Conversation \#2}

\section{Exploring the Ideal Role of Government, NGOs, Angel Investors, and Universities for Technology Entrepreneurs}

\section{Erik Hersman of BRCK}

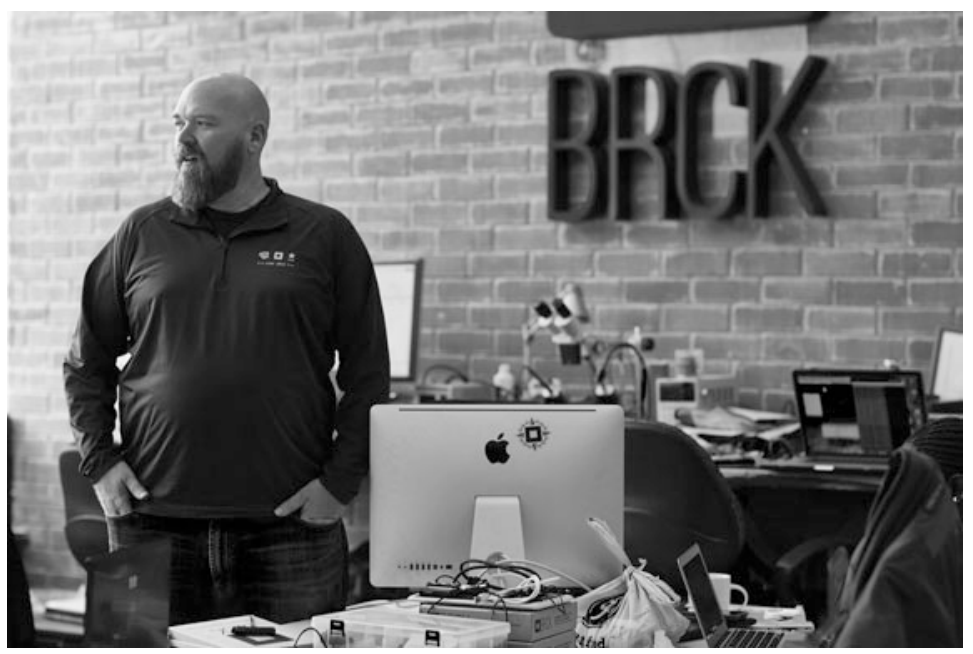

Erik Hersman is an entrepreneur and technologist focused on advancing the use of technology in Africa. He is the chief executive officer (CEO) of BRCK, makers of a wireless WiFi device designed and engineered in Kenya for use in emerging markets. In 2010, he founded the iHub, a pioneering innovation hub in Nairobi for the technology community, bringing together entrepreneurs, hackers, designers, and the investment community. He is also a co-founder of Ushahidi ("witness" in Kiswahili), a nonprofit company whose free open-source software is used to collect 
and map information for crowdsourcing, social activism, and public accountability; and of afrigadget.com and whiteafrican.com, online communities that explore Africa's creative solutions, entrepreneurship, and development challenges. He is also a general partner in the Savannah Fund and sits on the boards of Akirachix, Angani, the Kijabe Forest Trust, and the Whitaker Peace and Development Initiative. You can find him on Twitter at@WhiteAfrican.

\section{Erik, you are wearing multiple hats in Kenya's ICT sector. What is the story behind that?}

What gives me the right to do what I do rather than anybody else is actually what it comes down to. Well, nothing-besides that I am the one who did it, right? Anybody can do the same things I do! It just takes your desire and ability to champion something. I will go back into some of the history. So if you look back to 2005, that is when I started blogging about tech in Africa. Fast-forward three years from that, I had written about a lot of start-ups, I knew a lot of people, and I was part of the blogging ecosystem that was really burgeoning at that time. So it was a network of people who knew each other.

Then, we came across the post-election violence and craziness that were happening after the elections. Ushahidi was formed, and I was one of the founders. I remember that I came to Nairobi in August of 2008 and was sitting down with a bunch of other guys at BarCamp Nairobi. There was a large turnout. A great amount of interest, and there was everybody present. All the guys who are now CEOs of their own startups in the ecosystem, but we were still just ordinary tech guys at the time.

So, we were sitting around afterward, and we were saying, "Why is it that the tech guys in the city only meet up once or twice a year at these events? What if we had a place of our own?" And that was the seed that would eventually grow to become the iHub. So why did not somebody else do the iHub? Because it is a lot of work to come up with the money, to come up with the bigger vision of where this thing needs to be. And keep in mind that I was running operations for Ushahidi at that time, 
and actually through all of my time running the iHub, I still did. It is the ability to and the desire to champion an idea, even though there are way too many excuses not to do it. So how do you still push that idea forward beyond what your normal day-to-day job is? I think that is the biggest challenge. Look across the continent. Look at the people who are leading the tech hubs, generally. They are champions of the idea that we can build something together that is greater than any one of us and brings us all together in a different way. It is a desire to champion the idea and do the hard, scrappy work to get people together and convince people to show up for meetings and do all those little, oftentimes unnoticed things.

The iHub started, and that was after we talked to many people, asking, "Hey, will you give us some money for this or that and the other thing?" Nobody wanted to give us any money. Google and Nokia at the time, you name it. Nobody wanted to give us money. So finally, as Ushahidi, we sat down and said, "Listen, as Ushahidi, we can be a really good vector for the money that is needed for the iHub." And so that is what we did. Omidyar Network and Hivos funded Ushahidi and we built the foundations for the iHub with that.

But very early on, even before we had the space, I went out to people that were in the tech community already, that were my peers and people I respected and who were also respected by the general communitypeople like Becky Wanjiku, Conrad Akunga, Riyaz Bachani, and Josiah Mugambi. I said, "Hey, will you be the iHub advisors alongside me and help make the big decisions in the iHub's future, for the community?" We cannot make everything a purely democratic, everybody-votes-on-it process, but we can have a group of us who will help make some of the bigger decisions. And so, that was what we did.

When we first launched the iHub in March of 2010, Conrad Akunga told everybody, "Listen, here is the foundation. What gets built on top of this is up to you. Now, it's over to the rest of the community to help make this community what it is." And I think that is the kind of magic that makes the iHub, compared to most of the other tech hubs that are 
focused on incubation and other things. It is about the idea that we, as a community, need to be connected to each other and we need a space. We need a place, we need a meeting space that will allow us to almost accidentally find each other from time to time, which will draw us in and connect us in ways that would not exist if we did not have it.

\section{After Ushahidi and the iHub came Savannah Fund and BRCK. How do they fit into the picture?}

I think this is oftentimes deceptive. There are teams built around each of these ventures. Teams that are actually more involved in operations than I am. What happens is that there are obvious gaps in the market that need to be addressed. And if I put my name behind it, with, for example, Savannah Fund or with some other initiative-Gearbox is a newer oneit is not so much that I do anything day to day on it. I will sit there in board meetings and help with the ideation, the formation, the governance structure, but I do not have to be involved in the operations. It is more about finding the right people who capture the right vision of it.

So what hats do I wear? Now, I no longer wear this hat, but one that is relevant here was forming the Afrilabs Association and being the first chair for the initial years before passing it on. There is the Savannah Fund and being a general partner in it, but Mbwana Alliy actually runs it day to day. There is forming Gearbox, being on the board and helping create, but Kamau Gachigi leads it day to day. There is AkiraChix, which was the women in this community who built the whole thing, and they just asked me to join the board when they became an official organization three years into it.

And there is BRCK, which I spend $90 \%$ of my time on. I focus on BRCK because it is a venture-backed, for-profit company. All the other things take up that other $10 \%$, where I am just dipping in and helping as needed. The most valuable thing about me in each of these things is that, by being a part of it, I can either use my knowledge, network, or experience to help make decisions better and faster, but more importantly, I can help push things to actually get them done. There are a lot of people who talk about things, and there are very few people who do them. 


\section{Erik, there is a lot of controversy about government intervention into private-sector activities. What is your take? What should be the ideal role of government?}

So the role of the government is very simple: To reduce friction in the system for the technology industry to grow. What does that break down into? It breaks down into regulation that is actually good for businessspeed of setting up business, tax breaks for new companies, things like that. Another example of friction in the system that does not need to exist is legacy laws that are 30 to 40 years old and put a 20 to $30 \%$ duty on components imported into the country. I can import a fully assembled, packaged BRCK duty free. Yet the components to make it have a heavy import duty-which means it does not make sense to import. In other words, I cannot create a new manufacturing industry in Kenya if we do not have the ability to bring in raw materials that are not produced in Kenya. Like this, we never will create industries unless we change these legacy laws. So again, government's job is to reduce friction. And by reducing friction, they increase wealth and they increase jobs.

Then there are other things, such as providing foundational access, of which the subsidization of the undersea cable by the government was a massive example. That is exactly what the government should be doing, massive projects that bring in both the public and private sectors and help things move further. Another one is regulation around spectrum allocation or licencing.

\section{How about foreign aid and NGOs? What should their role be?}

In a well-functioning state, most NGOs would not exist. There is only a limited role for them, because the market answers many of the problems, and the government should answer the rest. However, here in Kenya, we have one of the highest count of NGOs per capita in the world. It is an interesting dynamic though, because international NGOs bring in money for some things, which bastardizes the market for other things. It creates a whole realm of craziness that you would not find in other places.

Let me give you an example. NGOs build bridges that after two years become dysfunctional. This cost a few million US dollars to make, and 
after two years, is no longer relevant. Other examples are new livestock programs in northern Kenya that only work as long as the NGO workers are there. As soon as they leave, it all falls apart. These are the kinds of things that we have seen for five decades now, and it does not seem to stop.

Now, if a business had this high of a failure rate, they would not keep operating. NGOs, however, seem to have a limitless amount of money that comes from unilateral and bilateral aid and just keeps on coming in. NGOs keep on having to fund something, and it goes a bit like this: "Oh, let's quickly procure something, because, shoot, we gotta spend this money before the end of the year." Or, "Hey, let's go fund innovation!" Not knowing what "innovation" means to them. They know that 80 to $90 \%$ of the money will be absorbed in overhead and HR costs instead of the innovation that the NGOs say they are going to fund. If you want to see innovation happen, then find vehicles where people are already doing interesting stuff and dump money into the companies that are growing great things and trying new models.

Having said all that, I think there actually is a role where international NGOs can help, and that is with government. That is, funding some of the regulatory research. Research so that laws can be made or something like public-private partnerships on large-scale intra-country projects, such as installing terrestrial cables. Helping to subsidize some of that stuff as it gets built out across the country is valuable, and if it can reduce some of the load on the government, then, sure, that can work.

As someone who runs a for-profit company, if someone wants to provide you with grant funding, you look at all that is going on in the market and you are to decide if it fits the company's focus and mission. I will take the free money if you hand it to me, but it has to be aligned with what I am trying to do. You need to dump money into me because what I am doing is great, not because what you are doing is great and you want me to do it for you. This type of decision is hard for younger executives, because it comes with some experience. If you are a leader of a company, you have to be strong enough to make the right call for your company. And if you are not making the right call and take a grant that does not 
make sense for your company, well, that is on you. Do not blame an industry because you made a bad decision.

\section{Angel investors are crucial in funding the ideational phase of a busi- ness. What is the current state in Kenya?}

For angels investors, those who have significant-enough disposable income to risk on investing, in Kenya it is a lot easier to put money into something like property and real estate. That is because we are seeing yearon-year growth of that. It is just astronomical! So it tends to be a smart decision to put your money into those things. What we are starting to see, however, are people in business who have made enough money that they are willing to diversify their portfolio out of just real estate. Where it has changed over the past two to three years is that we are seeing a few more people willing to dabble in tech investments locally. It is not large money-maybe USD25,000 here, USD100,000 there-but it is enough to get some companies off the ground. This will continue once angel investors start seeing a little bit of success, and this will bring in more of their peers.

Local angel investors can bring to the table more than what outside investors can offer. Outside investors largely bring in money and experience for early-stage company growth, strategy, and management. That is all good. But what they do not bring is connections to other businesses here in Kenya. Connections can immediately increase the share value of the business that the angels have invested in, and so, making the right introductions to CEOs or other companies is powerful. The problem currently is that angel money in Kenya is usually too expensive compared to money from abroad. If you have an investor coming in from the USA, they will give you USD50,000 and take $15 \%$ of your early-stage, prerevenue company. The Kenyan angel will give you USD50,000 and want $50 \%$ of your company, if not more. We need to find a balance where we decrease the cost of equity-based money from local angel investors and increase the knowledge base and connectivity of the money for outside investors. It should not just be money invested in a company. What actually needs to happen is that you are investing mentally and physically in the start-up in order to help it grow their company. 


\section{How do you see the current state of human capital development in Kenya for the next generation of entrepreneurs?}

I do not think universities will be the answer; at least, I have not seen them work for technology education. Graduates fresh out of university are, in general, not prepared to work in a technology company. They are not coming out of these institutions with the necessary skills. The people who do are usually the ones that are self-taught. That is quite disappointing. The universities in Kenya are too bureaucratic and not teaching the right stuff in the classes. Not across the board, but generally, students still learn the same computer languages that they were being taught eight years ago, even though current technology has changed.

Why are people still learning these things? And why are they not being challenged to learn new things? And why are university professors not the ones leading the charge on this? I like what the Moringa School is doing, and I like what a couple of the finishing schools for software engineers are doing. I think that is an interesting model and where we will see more hiring happen in the future.

I love bringing on people into my own company. The young people who have been self-taught and have a raw sense of what they should do. A raw skill set which allows building and growing them in my company. I think on-the-job training-whether it is for the Mike Macharias and Seven Seas of the world, or Safaricom, or Google, or IBM, or M-Kopa, or Intel-is actually one of the benefits of Nairobi. We have enough of those medium and large companies, and this is what sets us apart from Kampala and Kigali and Dar es Salaam. When you come out of university or even without university, you can get a job with Conrad Akunga or myself in our smaller companies. You can get a job with Mike Macharia at his company or with John Waibochi over at Virtual City or with any number of the smaller five-to-ten-person-size startups scattered across the city. There are a number of tech companies from small to large that are accessible to you, whereas they are not accessible in some of these other cities. The offtake of that is amazing. It means that there are more and more people who are being polished into seeing technology as a business opportunity. They develop an important and unique skill set. This does 
not necessarily happen in other places, simply because others do not have the critical mass of companies to even hire them.

\section{Reflecting upon the past years, can you point out one of the biggest "Aha!" moments that you have had?}

I think it is different for each stage when you are part of growing an ecosystem. I have been here for five and half years now. There are different things that happen throughout that time, and there are different things that matter, depending on the stage that we were in. The first "Aha!" moment was that this little idea of having a physical space would be good for the community. The "Aha!" moment was, "Holy crap, we're oversubscribed by 2,000 people and, yeah, it worked." The insight was this - that, yes, actual face time with people is important, even for technologists!

I had a conversation with Eric Schmidt of Google on his visit a couple years back. We were sitting downstairs grabbing lunch at Pete's, and I mentioned the numbers we were seeing and the success rates of those companies being around 10 to $15 \%$ for their first year. He responded that in Silicon Valley, the numbers are much, much higher, but the success rates are even lower-meaning that we should expect to put out many more companies if we want to see a few succeed at a very large level. This was the "Aha!" moment tied to the need to generate more start-ups. It is a numbers game. So how do we help get more things started?

We understand many will fail and that is fine. But the more we get out there, the better. It is like if you want the real, sort of bigger investors to come off the sidelines and jump into the system for more start-ups to scale, then we need at least one of them to exit at maybe USD20 million in order to prove to people that there is something here. That is what the ecosystem is figuring out right now.

For the iHub, the "Aha!" moment came as we realized that we did not have to charge our members if we come up with a service model that allows us to charge for other services, such as consulting. That is why we built the iHub Research arm, the UX Lab, and iHub Consulting. These 
new departments allowed the iHub to be $85 \%$ self-sustaining, generating its own revenue and still fulfill its mission of catalyzing the tech community in Nairobi.

I have realized over time that as you are figuring things out, it is important to be open to the idea that you really are experimenting and improvising a lot of the time. And if things do not work, you stop them. And if they do work, double down on them, and hopefully, it turns into another "Aha!" moment.

\section{Thank you, Erik!}

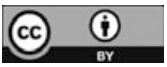

This chapter is distributed under the terms of the Creative Commons Attribution 4.0 International License (http://creativecommons.org/licenses/by/4.0/), which permits use, duplication, adaptation, distribution and reproduction in any medium or format, as long as you give appropriate credit to the original author(s) and the source, provide a link to the Creative Commons license and indicate if changes were made.

The images or other third party material in this chapter are included in the work's Creative Commons license, unless indicated otherwise in the credit line; if such material is not included in the work's Creative Commons license and the respective action is not permitted by statutory regulation, users will need to obtain permission from the license holder to duplicate, adapt or reproduce the material. 